\title{
Scott Memorial Lecture: The challenge of change
}

\author{
PHILIP E. GREENMAN, DO
}

The Scott Memorial Lecture was established in 1963 in honor of Katherine McLeod Scott, DO, and John Herbert Brice Scott, DO, for the purpose of providing lectures on or demonstrations of the original and basic techniques developed by $\mathrm{Dr}$ A. T. Still in the founding of osteopathy. The lecture fund was established by their daughter, Jeanette Scott Webster and her husband, Lawrence B. Webster, through the American Academy of Osteopathy. The list of Scott Memorial lecturers from the inaugural address to the present reads like a who's who of osteopathic medicine for the past quarter century. To join this illustrious group is indeed a great honor. I appreciate the opportunity.

The lecture presented here honors $\mathrm{Dr} \mathrm{A}$. T. Still, the founder of the osteopathic profession, and recalls his philosophy and the principles for which he stood.

Dr Still was one of many critics of orthodox medicine in the 19th century, but he was one of the few who left their mark on the healing arts. It was in 1874 that Dr Still first espoused his philosophy of medical practice- "flung out the banner of osteopathy" and attempted to share his vision with his medical colleagues.

\footnotetext{
Presented Oct 13, 1989 at the Kirksville College of Osteopathic Medicine, Kirksville, Mo.

Dr Greenman is a professor of biomechanics at Michigan State University-College of Osteopathic Medicine, East Lansing, Mich.

Reprint requests to Philip E. Greenman, DO, A407 East Fee Hall, Michigan State University-College of Osteopathic Medicine, East Lansing, MI 48824.
}

\section{The osteopathic philosophy}

Dr Still's genius consisted of his ability to synthesize basic biologic truths and astute clinical observations in a philosophy of healthcare. The premises of the osteopathic philosophy have been stated many times and in different forms. In 1953, the faculty of the Kirksville College of Osteopathic Medicine set forth four basic premises ${ }^{1}$ :

- The body is a unit.

- The body possesses self-regulatory mechanisms.

- Structure and function are reciprocally related.

- Rational therapy is based on an understanding of body unity, self-regulatory mechanisms, and the interrelationship of structure and function.

In 1963, a special committee of the American Osteopathic Association ${ }^{2}$ (AOA) approved an expanded statement:

- The human body is a unit in which structure and function are mutually and reciprocally interdependent.

- The body, through a complex equilibrial system, tends to be self-regulatory and selfhealing in the face of disease processes.

- Adequate function of body systems depends on the unimpeded flow of blood and nerve impulses.

- The musculoskeletal system comprises one of the several body systems, and its importance far exceeds that of providing framework and support.

- There are somatic components to the disease which are not only manifestations of disease, 
but are important contributing and/or maintaining factors. These somatic components may be local or distinct. Appropriate treatment of them has great value.

The concepts of self-regulating mechanisms and self-healing processes are as old as medicine itself and have been attributed to Hippocrates. Likewise, the use of manipulation as a therapeutic modality has its roots in antiquity and can be found throughout the history of medicine. The concept of the interrelationship between structure and function was championed by the pathologist Rudolf Virchow, a contemporary of Dr Still's. Dr Still, then, met the challenge of 19 th-century medicine by developing a philosophy of holistic patient care.

Dr Still's new philosophy and practice of medicine was a challenge to his colleagues. Despite his attempts to share his ideas, he was rebuffed by his fellow physicians. Undeterred, he continued to practice successfully this new form of medicine.

\section{Formalization of osteopathic medical education}

The history of Kirksville in the late 19th century is fascinating. ${ }^{3}$ Dr Still was able to attract patients from the East Coast and from across the Atlantic Ocean. In those days, travel was not so easy as it is today, and Kirksville was not easy to get to (and that continues to be true). Such was Dr Still's success that it became necessary to schedule additional trains to bring patients to Kirksville and to build additional hotels for them to stay in. What it must have been like to be in Kirksville in those days!

For assistance in patient management, Dr Still trained the members of his family in the art and science of osteopathy. Many other men and women came to study with him as well, and it soon became apparent that it would be necessary to formalize osteopathic medical education. In 1892 at the age of 64 , Dr Still founded under charter from the state of Missouri the American School of Osteopathy. His purpose was

... to establish a college of osteopathy, the design of which is to improve our present system of surgery, obstetrics, and treatment of diseases generally, and place the same on a more rational and scientific basis, and to impart information to the medical profession, and to grant and confer such honors as are usually granted and conferred by reputable medical colleges. ${ }^{4}$

I continue to be fascinated with the phrase "to improve our present system of surgery, obstetrics, and treatment of diseases generally." My interpretation is that Dr Still wished for all medical practitioners to become osteopathic and that he did not intend to keep the medical truths of osteopathy cloistered and separated from orthodox medicine. Thus, the first academic health center in osteopathic medicine was founded.

\section{Challenges to the osteopathic profession}

The profession grew rapidly, and it was challenged repeatedly. The first major challenge was for recognition of the DO degree that Dr Still had chosen for his medical school graduates. In the late $1890 \mathrm{~s}$, the first of many legal battles for medical licensure was joined, and in 1898 , Vermont became the first state to grant licensure to an osteopathic physician. The battle was to continue for the next 75 years. Only since 1974 have full practice rights been available in all 50 states to osteopathic physicians. The profession met the challenge to obtain licensure, expending in its ultimately successful campaign much of its precious and limited resources of time, talent, and treasure.

In the first half of the 20th century, as the medical knowledge exploded and medical and surgical care became more hospital based, the profession was challenged to obtain hospitals if it was to continue as a total health profession. When denied access to the available hospital system, the profession built its own institutions. ${ }^{5}$ Most of these hospitals were built by the members of the profession themselves, with little community support. Once founded, the osteopathic hospitals were able to attract support for maintenance and growth from various levels of the community and government. Today, the osteopathic hospital system is under serious challenge, and we should all be concerned.

Concurrently with the development of hos- 
pital-based medicine and surgery, the osteopathic medical profession was challenged to obtain access to specialty and subspecialty education to keep up with the rapid advances in the art and science of medicine. To expand their medical knowledge and skill in specialty areas, DOs traveled to Europe or surreptitiously gained access to specialty training programs in the United States. These osteopathic pioneers returned to the profession and established residency and preceptor programs to train others. The profession developed quality residency and fellowship training programs and a certifying-board system to recognize osteopathic physicians who demonstrated competence and proficiency in specialty areas.

Throughout the first six decades of the 20th century, a period of growth and maturity of the osteopathic profession, the political arm of orthodox medicine attempted to thwart the profession at all times and at all levels. Its major attempt to obliterate the profession occurred in the California merger of the osteopathic into allopathic profession in 1962 . The profession was seriously challenged and forever changed as a result. We lost a college (College of Osteopathic Physicians and Surgeons, Los Angeles), the largest state society of osteopathic physicians and surgeons, a large number of osteopathic hospitals, and graduate medical education training sites.

It is interesting to speculate about what would have happened if the promises made to the osteopathic profession in California had been fulfilled. What would have happened if osteopathic specialists had been granted recognition by American Medical Association certifying boards? What would have happened if the California DOs had become members of their local/county medical societies rather than being placed in a separate statewide organization? What would have happened if the promised research into questions about the validity of osteopathic medicine had been pursued sincerely?

We will never know the answer to these questions because these things didn't happen. Instead, the osteopathic medical profession gathered itself together and was never more unified. It met this serious challenge by develop- ing a new school to replace the college that had been lost in California. The Michigan College of Osteopathic Medicine, founded as a private school in 1969, which became the Michigan State University-College of Osteopathic Medicine in 1970, was the first new college of osteopathic medicine to open in more than 50 years. Since then, nine new colleges of osteopathic medicine have been developed. Some say that we have too many schools; others say that we have too few. The future of the profession was placed in its academic arm. ${ }^{6}$

As a learned profession, osteopathic medicine must meet the triple challenge of teaching, research, and public service. This threelegged stool, if you will, is classically exemplified by the academic health center. Although allopathic medicine has many fine academic health centers, the osteopathic professionbecause of many circumstances-has very few. The challenge to us today is to develop and sustain osteopathic academic health centers. How are we to meet this challenge? Let us explore five elements of the academic health center and see how the osteopathic profession might posture itself for change.

\section{Osteopathic healthcare system and the academic health center}

\section{High-quality care}

The first requirement of the successful academic health center is that it be able to provide high-quality healthcare. Historically, much of the quality healthcare has been offered in tertiary-care hospitals. Today, however, the healthcare delivery system is rapidly changing. The single tertiary-care institution has been replaced by broad-spectrum systems, including ambulatory-care centers and community hospital networks with a tertiary-care capability.

The osteopathic medical profession by its small size and diffuse distribution has very few organized healthcare systems that meet today's definition of academic health center. The vast majority of our hospitals are community based. The vast majority of our practitioners practice alone or in small groups. Only just recently have we begun to develop larger multidisciplinary group practices in which ac- 
cess to full-scope medical and surgical specialty and subspecialty care can be offered.

Not only are we challenged by the small size and diffuse distribution of our institutions, but more important, we are challenged to demonstrate that our healthcare is sufficiently distinctive, to warrant support as a separate profession. We are challenged to demonstrate to decision makers, in both the public and the private sectors, that there is something "osteopathic" about our healthcare system. Today, the challenges to the osteopathic hospital are more economic than philosophic. In the past 3 years, the number of osteopathic hospitals has declined from 195 to 178 . However, if the care rendered in osteopathic hospitals is demonstrably valuable to society, I have no doubt that society will see that it is continued.

We need to sustain, as best we can, the osteopathic healthcare system so that we can continue to educate our students at the graduate level as well as at the predoctoral level. From an administrative point of view, it will be difficult to organize our osteopathic healthcare system as academic health centers, but it is essential to do so if we are to survive as a profession.

\section{Graduate medical education}

The second component of the academic health center is its graduate programs, in medical education, both $\mathrm{PhD}$ and post-professional-degree education. The osteopathic profession has rarely had the resources available for $\mathrm{PhD}$ education, but now some of the newer schools that are affiliated with universities are able to offer doctoral programs. Currently, it is within the area of post-DO graduate medical education that we face our greatest challenge. Quality doctoral and postdoctoral programs include exposure to patient care and opportunities for basic, applied, and clinical research.

Currently, more than $50 \%$ of the graduates of colleges of osteopathic medicine pursue their residency training in nonosteopathic institutions. This phenomenon presents a serious challenge to the profession and its long-term viability. While these DO residents have new and unique opportunities for graduate medical education, how osteopathic are their pro- grams? How osteopathic is the care that they are learning to provide? How osteopathic are the research questions they pursue? Many graduates of these quality residency programs have returned and strengthened our profession. Others, including some of our brightest people, have been lost.

I am pleased that the AOA has recently developed a process for recognizing nonosteopathic graduate medical education so that our loss of quality people can be reduced. I am disappointed that it did not adopt the recommendation that the residents of these programs be offered a supplemental program in osteopathic principles, practice, and procedures appropriate to their specialties. We must see that our graduate medical education programs become strong enough to compete in quality with those offered by our sister profession and that they provide, in addition, training that will indeed make osteopathic specialists.

\section{Research opportunities}

The third component of the academic health center is a research milieu. A learned profession must generate new knowledge and share it with the scientific community at large. Research under osteopathic institutional direction has been limited, in large measure because of the paucity of resources. We meet on the campus of an institution that has recognized the need and provided resources for the pursuit of scientific knowledge.

All of our institutions need to do more in the way of basic and clinical research on questions relating to the osteopathic experience. "What is osteopathic research?" people ask. I do not believe that one does "osteopathic research." One researches questions and tests hypotheses that have been formulated in the 100 years of clinical experience by the osteopathic medical profession, experience that has stood "the test of time."

There must be answers to those questions from the osteopathic experience that are worthy of pursuit, questions that could attract the time and talent of skilled researchers and for which academic administrators could acquire the necessary resources. The clinical research must be carried out within a framework of 
truly osteopathic healthcare because it is impossible to teach or to investigate that which one does not do. If we are to teach and research osteopathic medicine, we must practice osteopathic medicine.

\section{Osteopathic medical training}

The fourth component of the academic health center is that area in which most osteopathic medical education occurs - the predoctoral educational program. Historically, new colleges of osteopathic medicine have been developed by the acquisition of a facility, a small basic science teaching faculty, and a few osteopathic clinicians (some of whom have donated their time for the endeavor) and the enrollment of an inaugural class. There has been little planning and development of the students' graduate medical education or, in fact, of the clinical education portion of the predoctoral program. Although it may have served us well in the past, this model is no longer feasible.

Along with the limitation of graduate medical education sites, we also face severe constraints on the availability of clinical education sites for our predoctoral students. Our students should be educated in milieus in which they see quality osteopathic healthcare, quality graduate osteopathic medical education, and quality research into questions on the osteopathic medicine experience. They must be consistently challenged to pursue the scientific method of inquiry and not learn to practice osteopathic medicine by rote. Our colleges are the lifeblood of the profession, and we must continue to graduate a product that meets the ever-expanding need of the society for quality healthcare.

\section{Allied-health-professional education}

The fifth area of the academic health center is that of allied health. Historically, osteopathic medical institutions have not had the resources necessary to educate allied health professionals and have been criticized for relying on the traditional system for nursing staff, radiologic technicians, laboratory technicians, and other allied health professionals. In recent years, however, many osteopathic medical institutions have become universities and have developed and offered educational programs in podiatry, pharmacy, physician assistants, and other fields. The benefit of educating allied health professionals in an osteopathic academic health center is their understanding of the uniqueness of osteopathic medicine.

\section{Future challenges}

Our challenge for the future, then, is to develop academic health centers that deliver high-quality healthcare and that provide graduate medical education, research opportunities, osteopathic medical training, and an alliedhealth-professional education. We must find ways to organize the profession in a fashion that allows us to develop these centers of academic excellence. To do less will doom us to becoming a group of trade schools. To do less will deny us the opportunity of fulfilling Dr Still's dream to "improve the system of medicine and surgery in general."

I submit that the future challenge to the osteopathic profession is to put itself out of business by demonstrating the basic biomedical truths that undergird the practice of osteopathic medicine to the worldwide medical community and to persuade all medical schools and medical practitioners to integrate and use the osteopathic medicine philosophy as the basis of patient care. If the osteopathic medicine philosophy is as valuable as I believe it to be and if the integration of structural diagnosis and manipulative treatment into healthcare is as valuable as I believe it to be, then we have little to fear for the loss of osteopathic medicine. Osteopathic medicine will survive, but may have its name changed, as the merits and strengths of osteopathic methods are discovered even as many members of the profession continue to deny their value and use to their patients.

In the United States, healthcare is in an economic and organization crisis. It is undergoing a rapid and dynamic change. In the next generation, the practice of osteopathic medicine will clearly differ from all previous practice. Challenge and change are part of progress. The challenges and the changes that occurred in Dr Still's lifetime were quite differ- 
ent from ours. Dr Still and his colleagues met the challenges of their day; they made changes; they showed us the way. Are we prepared to meet new and different challenges? I hope so.

1. The osteopathic concept as interpreted by osteopathic colleges. JAOA 1962;61:407-409.

2. Basic philosophy of osteopathy and the contribution of the osteopathic profession to health care. Prepared by Special Committee of the Council of Development, American Osteopathic Association, approved May 1963. Chicago, American Osteopathic Association, 1963.

3. Gevitz N: The DO's: Osteopathic Medicine in America. Baltimore, The John Hopkins University Press, 1982.

4. Northup GW: Osteopathic Medicine: An American Reformation, ed 2. Chicago, American Osteopathic Association, 1979.

5. Greenman PE: Osteopathic hospitals: Playing a unique role in public service. Osteopathic Hospitals January 1978, pp 8-10.

6. Greenman PE: Outcome of an osteopathic medical education center. The DO 1975;15(10):130-132.

7. Beckwith CG: The test of time, in Yearbook of Academy of Applied Osteopathy. Carmel, Ca, Academy of Applied Osteopathy, 1963, pp 7-13. 